\section{SCORECARD}

\section{Curry \\ Japanese curry-lovers can now experience}

the taste of space, as pouches of curry identical to those eaten on the International Space Station have gone on public sale.

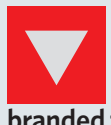

\section{Bacon \\ The World Cancer Research Fund has} one of the top food no-nos if you want to avoid cancer.

\section{ZOO NEWS}

\section{Dolphin danger}

Conservationists want to stop children with disabilities such as autism from swimming with dolphins. Far from being therapeutic, they say the aquatic mammals' play is a danger to kids.

\section{ON THE RECORD}

\section{(cAn airport with 50} million passengers and countless take-offs and landings per day is not the place for a large wild cat community.)"

Pasquale DiFulco of the New York port authority explains the city's decision to round up the estimated 75 feral cats roaming JFK airport.
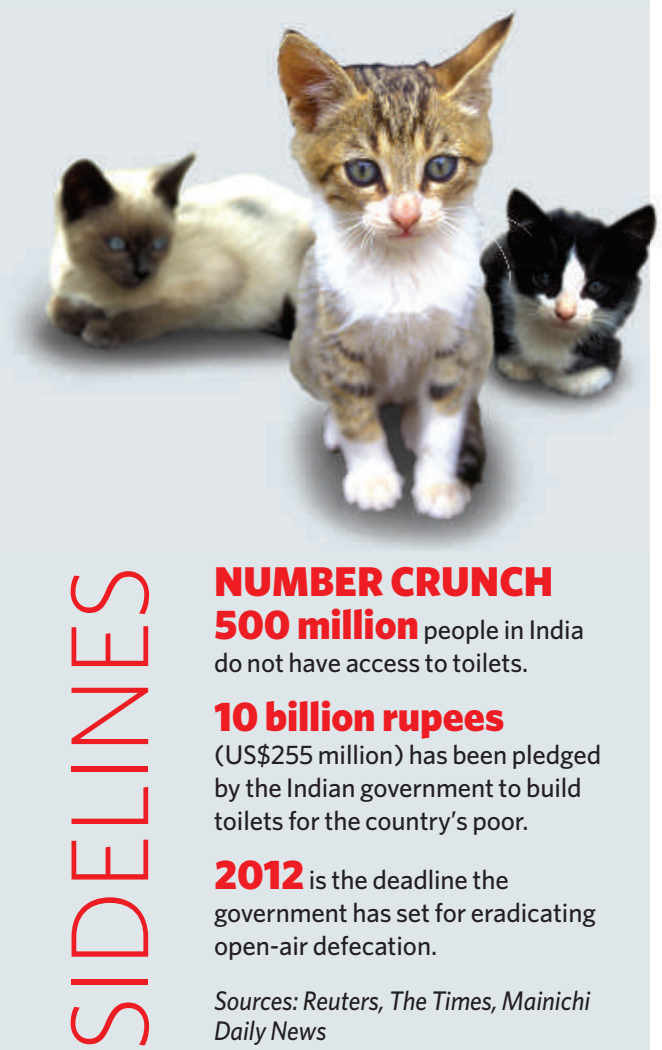

NUMBER CRUNCH 500 million people in India do not have access to toilets.

\section{0 billion rupees}

(US $\$ 255$ million) has been pledged by the Indian government to build toilets for the country's poor.

2012 is the deadline the government has set for eradicating open-air defecation.

Sources: Reuters, The Times, Mainichi Daily News

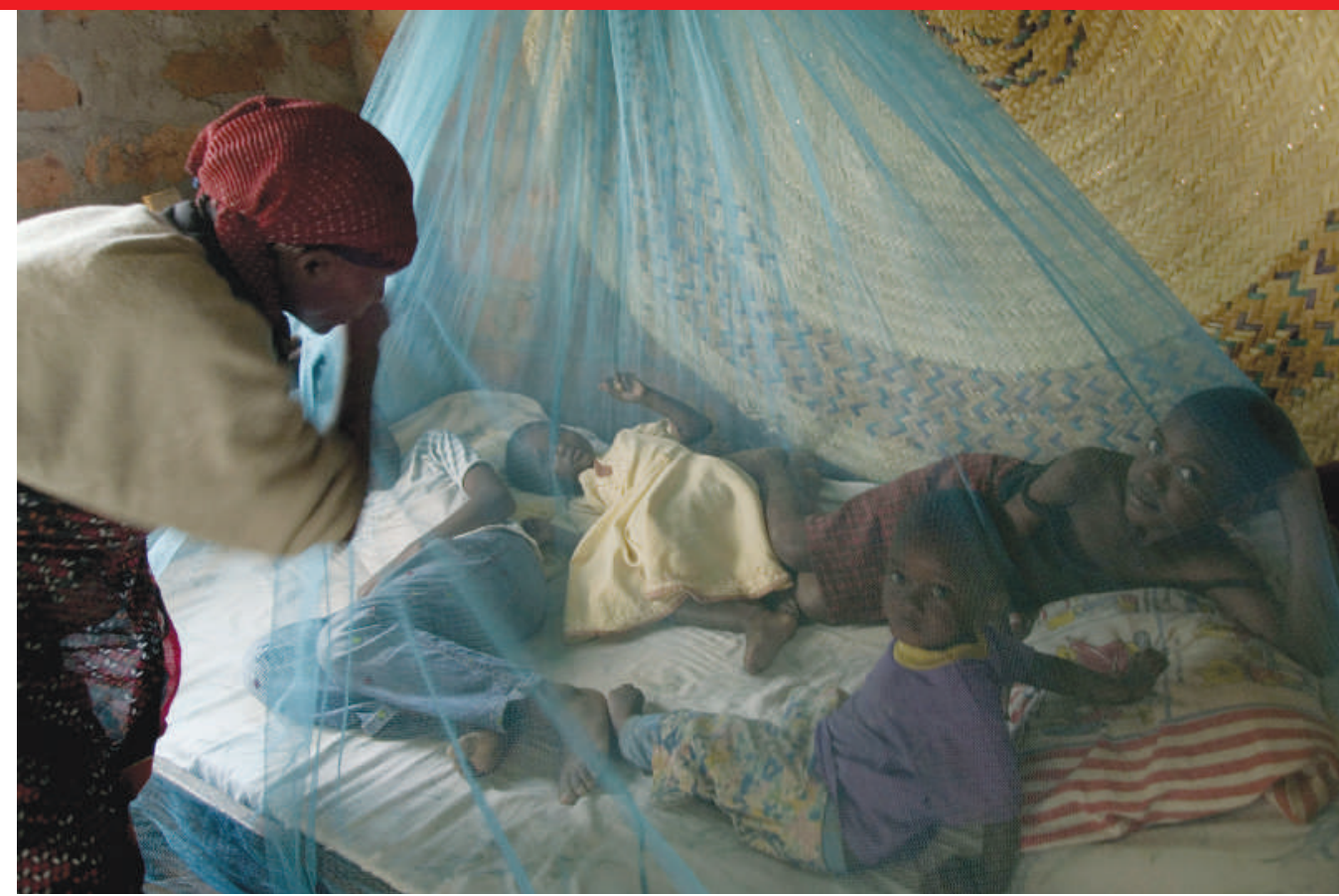

\title{
Poor follow-up hampers malaria projects
}

The incidence of malaria in some African countries may soon approach that of the eastern Mediterranean as a result of increased use of insecticide-treated mosquito bednets, spraying and more effective drugs. The first analyses of the effects of such interventions in the field indicate that they have had a direct and major effect on the malaria burden in Kenya and in Tanzania’s Zanzibar archipelago.

However, a lack of global coordination on eradication projects and poor data evaluation are jeopardizing malaria-control programmes in the worstaffected parts of the continent. Studies of the actual impact of control programmes on public health and mortality are surprisingly few, and as a result there is a worrying paucity of data.

"The biggest flaw in current malaria-control efforts is that we need to invest more in disease surveillance systems to know the true story of what is really happening in Africa," says Mark Grabowsky, Malaria Program Manager at the Global Fund to fight AIDS, Tuberculosis and Malaria. What's needed, says one prominent international health official who wishes to remain anonymous, is a greater international focus to put in place tools to compare data and standardize protocols. This has been achieved for diseases such as polio and measles, in which standardized data are available by district and month in Africa. There are no data of comparable quality for malaria, he says, adding that most reports of successes have been anecdotal.

One study to evaluate the success of these pro- grammes was carried out by Bob Snow's group at the Kenya Medical Research Institute (KEMRI)Wellcome Trust Collaborative Research Programme in Nairobi, and an international team The researchers found that paediatric malaria admissions at hospitals on the Kenyan coast have fallen by up to $63 \%$ since 1999 , as a result of interventions such as new drugs called artemisinin-based combination therapies $(\mathrm{ACTs})^{1}$. Snow's group also studied about 3,500 children in 72 rural areas of Kenya and found that bednet use was linked to a $44 \%$ reduction in mortality ${ }^{2}$.

Snow says he is convinced that the decreases in malaria in Kenya are a direct result of the rise in bednet coverage in the zone between 2004 and 2006 from $7 \%$ to $67 \%$ of children, and the fact that $85 \%$ of rural clinics now stock ACTs that were non-existent only a few years ago. "I think we are going through an epidemiological transition because of scaling up of intervention coverage," says Snow, who believes that the epidemiology of malaria in many African countries is as a result shifting closer to that of the eastern Mediterranean region, where malaria incidence is at a more containable level of fewer than 10 in every 1,000, compared with 350 in every 1,000 Africans.

Data from Zanzibar, published this week by Achuyt Bhattarai at the Karolinska Institute in Stockholm and his colleagues, also show that malaria deaths dropped to one-quarter of previous levels between 2002 and 2005 after the introduction of ACTs and widened use of bed- 
nets ${ }^{3}$. Similarly encouraging preliminary data are coming in from Ethiopia, Eritrea, Mozambique, South Africa and Rwanda.

But collecting and analysing rigorous data is difficult. Snow had to ensure that his data covered a long enough period, and that his models accounted for rainfall and other factors that make teasing out the direct impact of interventions difficult.

Until now, most of the data have emerged in a fragmented way from organizations with a vested interest in the figures released. A report that has been billed as a success story, released by the United Nations Children's Fund (UNICEF) on 17 October, showed that annual global production of insecticide-treated bednets soared from 30 million nets in 2004 to 63 million nets in 2006, and orders of artemisinin jumped from 3 million doses in 2003 to 100 million in 2006.

But experts argue that such organizations often release data more for advocacy than to assess operations. The spin on the figures masks the fact that all countries are far short of the targets set by Rollback Malaria of $80 \%$ coverage of all interventions by 2010 - most have not achieved a fraction of that.

One key test will be in Zambia, in a programme launched in 2005 and funded by the Bill \& Melinda Gates Foundation. It aims to reduce deaths from malaria by $75 \%$ by 2008 , through a huge scale-up of bednets, drugs and house spraying. Results submitted for publication show that in households with bednets, parasite prevalence in children and anaemia in infants fell from about $20 \%$ to $13 \%$. At the end of 2006 , the project had $20 \%$ of children under bednets; $40 \%$ of households owned a net; and spraying reached $34 \%$ of targeted households. In absolute terms these are still "miserably low numbers", points out one expert, adding that the overall malaria effort falls far short of its own targets.

The few countries where progress on mortality is being reported all fall within zones in Africa that are moderate both in terms of the intensity of transmission (the number of infected mosquito bites per person) and the length of the malaria season.

No one has yet shown a reduction of malaria in countries such as the Democratic Republic of Congo and Nigeria, where transmission rates are so high that preventative measures might have little impact on mortality. These two countries alone account for around half of malaria mortality in Africa, but poor management and health systems mean that they remain laggards in implementing malaria control measures, let alone evaluating their impact.

Declan Butler

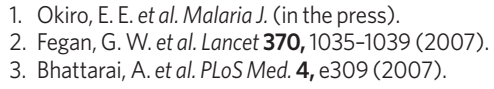

\section{Committee releases shortlist of Mars landing sites}

Six potential landing sites have been chosen for NASA's Mars Science Laboratory, a large rover set to assess the past habitability of sites on the planet's surface, when it lands in October 2010. The shortlist, chosen from dozens of possibilities, includes craters partly filled with sediment, an ancient flood channel and regions rich in clay minerals thought to date from an era when the martian surface was wetter than it is today. However, changes to the mission's scope mean that options that might offer excellent science could end up being dismissed as impractical.

The mission has a 'landing ellipse' roughly 20 kilometres across to account for the uncertainties involved in guiding a spacecraft over millions of kilometres to a soft landing on a windy planet. The terrain in the ellipse needs to be smooth and flat. "If you ask an engineer, they'd like to land in a Walmart parking lot," says Jack Mustard, a planetary geologist at Brown University in Providence, Rhode Island.

As originally conceived, once landed, the rover would have been able to travel well outside this ellipse to places neither smooth nor flat - the sorts of outcrop that geologists favour. But participants at last month's workshop to choose the candidate sites, hosted by NASA's Jet Propulsion Laboratory in Pasadena, California, found that sites where the rover would need to travel 10 kilometres or more to obtain samples were now being flagged as possibly problematic.

"I would have been screaming at that," says Ken Edgett, of Malin Space Science Systems of San Diego, who is a principal investigator on the mission but was unable to attend the workshop because of the wildfires in California. "It limits your expectations," says Mustard, who favours a site in the Nili Fossae region from which the rover would be able, if all went well, to sally forth to a region of dramatic erosion that he has dubbed Monument Valley.

Changes in the way that the rover's moving parts will be lubricated raise issues for sites in the planet's southern highlands, as they reduce the rover's capabilities in winter parking lot." conditions. Nevertheless, the scientists shortlisted two southern sites as worthy of further study. One of them, Holden Crater, contains what seem to be lake sediments and a delta. "It's awesome," says Mustard.

The shortlisted sites will now be scrutinized further by instruments on board NASA's Mars Reconnaissance Orbiter, which is currently circling the planet. At the same time, computer models will assess the risk of winds at the sites being strong enough to mess up the landing. It is very unlikely that all six will be considered too risky, says John Grant of the Smithsonian Institution's Center for Earth and Planetary Studies in Washington DC and co-chair of the siteselection committee. The final decision does not need to be made until nearer the launch in October 2009.

Oliver Morton

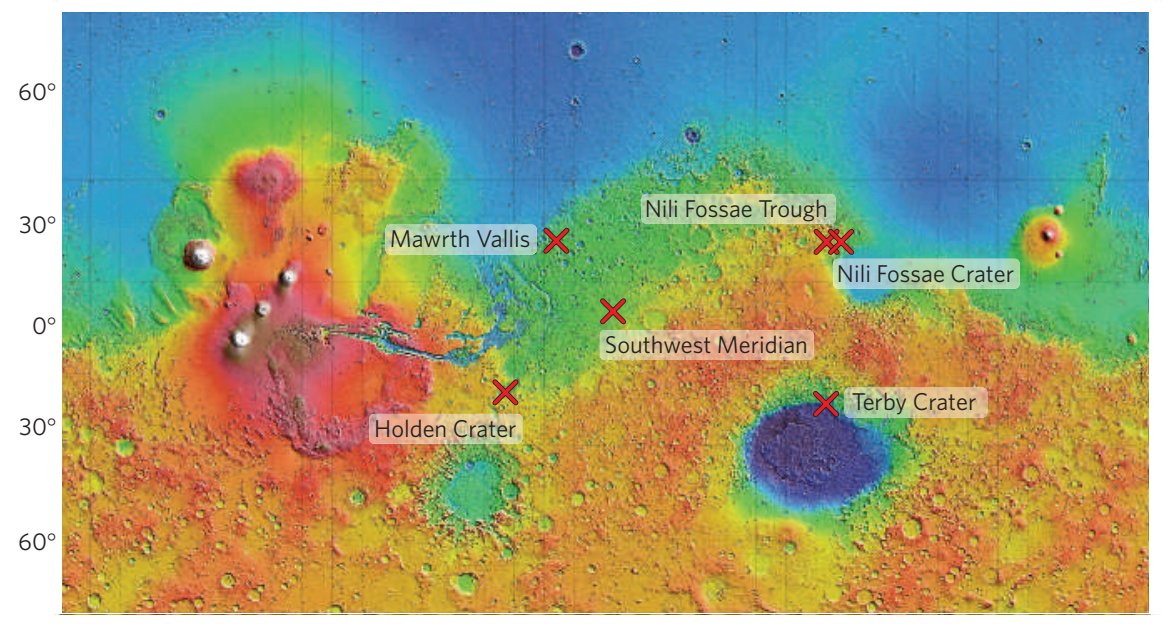

Mars projection with shortlisted landing sites, two of which are in the southern hemisphere. 